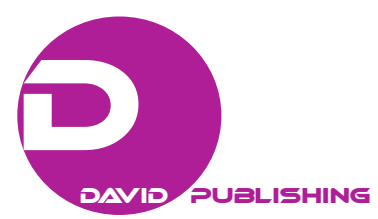

\title{
Professional Identity of Teachers in China ${ }^{*}$
}

\author{
Wang Li \\ Quzhou University, Quzhou, China
}

\begin{abstract}
Teachers' professional identity plays an important role in teachers' teaching and attitudes towards education. Therefore, teachers' professional identity has already got researchers' attention in educational field of China, and a lot of study and research has been done on it. The study generalizes that the level of teachers' professional identity is low in China by reviewing the results of previous research in relevant aspects. Through analysis, the study finds that teachers' low professional identity in China is caused by teachers' overwork, unreasonable evaluation systems, and relatively low income. Finally, the study suggests the government and schools solve the problem by improving teachers' economic status, establishing scientific and reasonable evaluation systems for teachers, and improving teachers' mental health state.
\end{abstract}

Keywords: professional identity, teachers, income, evaluation system, mental health

\section{Introduction}

On the evening of April 27, 2012, in the teacher's office of Guantao No.1 Middle School, Hebei Province, on the desk were an empty bottle labeled with "dichlorvos (DDVP)," a "sleeping" middle-aged young man and a farewell letter with only a few words that seemed so "heavy." All these constituted the tragedy of Zhao Peng.

Zhao Peng, born in 1982, worked as a class teacher in Senior Grade Three of Guantao No.1 Middle School after graduating from college. His daily routine began with the morning exercise with Senior Grade Three students and ended till the students went to bed at night day after day. Perhaps suffering from the pressure from life, work, economy, and some other aspects, he chose to commit suicide at a so early age. In his suicide letter, he said, "Life is really tiring, with endless work everyday so suffocating, with wages nearly used up every month. I decide to leave in this way. I do not hate this place, for it was my own choice to come here after all. Now, my only concern is my son. My only hope is the school can help me to look after my son and my wife” (Liu, 2012).

In recent years, a lot of teacher-suicide news could be found online in China. For example, an English teacher working in Yucai Middle School in Guangzhou committed suicide on October 24, 2008 because of mental depression as she had failed in getting the senior professional title (Lian \& Liao, 2008). On April 15, 2015, an excellent 39-year-old teacher working in Yangjiang Town Central School in Qionghai, Hainan killed himself because of too much work pressure (Liao \& Wang, 2015). What underlines all these tragedies is no doubt that working pressure, psychological pressure, and life pressure have given current teachers such a hammer blow that most of them have low or negative professional identity.

Professional identity means a person from the bottom of his heart thinks his career valuable, meaningful, and able to offer fun. For everyone in the workplace, professional identity is important, because only the

\footnotetext{
*Acknowledgement: This paper is supported by the Key Disciplines of Quzhou University.

Wang Li, master, lecturer, College of Foreign Languages, Quzhou University.
} 
recognition and love for the career can make people fully devoted to it (Azman, 2012). On the contrary, if a person feels bored or even dislikes the job, it is hard to arouse his enthusiasm for the work. As for the teachers who bear the responsibility of cultivating students, their professional identity is of extreme significance, because the young generations are the future and hope of a country. But now in China, many teachers are not satisfied with their career, though it seems that teacher is a good job in the public eye. According to the survey launched by Xiaokang, of 100 teachers interviewed, 50\% said "No." to the question "Have you got professional happiness as a teacher?” and 75\% said they might or decided to change a job (E, 2013), which also reflects the low professional identity of teachers in China.

In addition, the negative professional identity of teachers in China can partly be revealed in the state of their mental health. In 2016, a research group from Bijie Preschool Education College carried out a comprehensive survey on the mental health state of primary and secondary school teachers in Bijie, China. The result shows that among the 1,440 teachers surveyed from eight primary and secondary schools, nearly 46.39\% have psychological problems and 11.81\% have mental disorder (He, Yang, Jiang, Yang, \& Wang, 2016). What has caused so many danger signals?

Due to the school entrance system in China, the score is everything. Students' performance in entering a higher school is closely linked to teachers' vocational certificates assessment and merit pay. In other words, entrance score determines teachers' status in the school and income. At the same time, teachers begin to face more and more challenges as the education reform has been carried out everywhere. Generally speaking, teachers have to bear not only the heavy work and huge psychological burden, but also the pressure from students' parents and public at any time. On the other hand, many teachers lead a hard life in the face of rising prices due to the low income. In the research carried out by Lu, Gao, Yan and Sun (2014) on the economic status of primary and secondary school teachers in the rural area of Hebei province, for most teachers surveyed, their monthly income is barely enough for their household expenses, with housing costs not included. What's more, without institutes and solutions specially dealing with teachers' mental problems, there is no suitable channel for teachers to unbosom their feelings and worries. Some schools have psychological counselors only for students, so over a long period, the low professional identity of teachers would gradually evolve into psychological problems, even one day generate catastrophic effects, bringing serious influence and harm to themselves and students, thus how to maintain and improve teachers' professional identity is a topic of practical significance.

In the past years, the government and schools have spent both great efforts and money to carry out various kinds of teacher training programs, which to some extent successfully make most teachers more professionally competent for their highly-required job. However, the inner-self of teachers has been ignored most of the time, and the existing problems haven't been solved. Only when teachers' unbearable burden and pressure are lightened can those tragedies be avoided. In a word, changes need to be made in teachers' income, evaluation system, and mental health state in order to foster teachers’ professional identity.

\section{Low Professional Identity of Teachers in China}

During recent years, teachers' professional identity has aroused a lot of concern in China. Teachers' professional identity refers to the emotional experience and psychological feelings produced by teachers (both as individuals and professionals) towards the work they engage in, which is being affected by various factors inside and outside the school and teachers themselves (Goodson, 1994). Professor Shen Jiliang, the director of 
the Institute of Psychological Development of Beijing Normal University, believes professional identity is becoming the inner motive power for teachers to achieve self-improvement ( $\mathrm{Li}, \mathrm{Li}, \&$ Shen, 2012). Teacher is a special profession that is not only related to the future development of the teachers themselves, but also has a long-term and irreversible influence on a student's future, so it is particularly necessary for teachers to construct a solid professional identity (Connelly \& Clandinin, 1999). Meanwhile, teachers' satisfaction towards their jobs, work pressure, and burnout feeling level affects professional identity most (Li, Li, \& Shen, 2012).

Cassel (1984) stated that if a person has to do the work he has no interest in, he will feel bored and in a kind of exhausted mental state, which leads to difficulty in giving full play to the potential and ability, and drops of working efficiency. Such kind of state is called job burnout. Now, job burnout is quietly infecting an increasing number of "engineers of human soul." In 2005, the Institute for Organization and Human Resources of Renmin University and Sina Education Channel jointly launched the Chinese teachers' occupational stress and mental health survey. As can be seen in Figure 1, 34.60\% of the surveyed teachers reflected the pressure was too much, and $47.60 \%$ reflected the pressure was heavy, which together accounted for $82.2 \%$ of the surveyed teachers $(\mathrm{Li}, 2005)$. What is more, in Figure 2, the result of the survey shows that $27.5 \%$ of the surveyed teachers had at least mild job burnout feeling, $29.50 \%$ of surveyed teachers had moderate job burnout, and $29 \%$ of the teachers surveyed are in accordance with the highest job burnout level (Li, 2005).

Students' psychological health has been attached much more importance in China, teachers' psychological health problems, however, have been ignored for a long time. At present, the psychological health state of primary and secondary school teachers is worrying, which partly indicates the negative professional identity of teachers in China. As is demonstrated in Chinese teachers' occupational stress and mental health survey, $38.50 \%$ of the teachers surveyed had poor mental health, and only $28.80 \%$ of the surveyed teachers' were mentally healthy (Zhang \& Lu, 2008). Another survey about primary and secondary school teachers' psychological health state in Bijie found that $46.39 \%$ of the teachers involved had different degrees of psychological problems or mental disorders, 33.47\% had obsessive-compulsive disorder, $22.36 \%$ had interpersonal sensitivity, 24.37\% had melancholia, and 20\% had anxiety (He et al., 2016). Although the statistics vary from areas, what should be paid great attention is that our country's primary and secondary school teachers' psychological health problem is very serious.

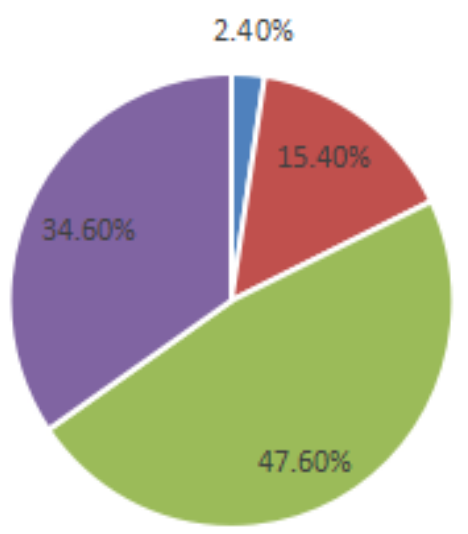

n No Pressure a A Little Pressure a Much Pressure a Too Much Pressure

Figure 1. Occupational stress of teachers in China. 


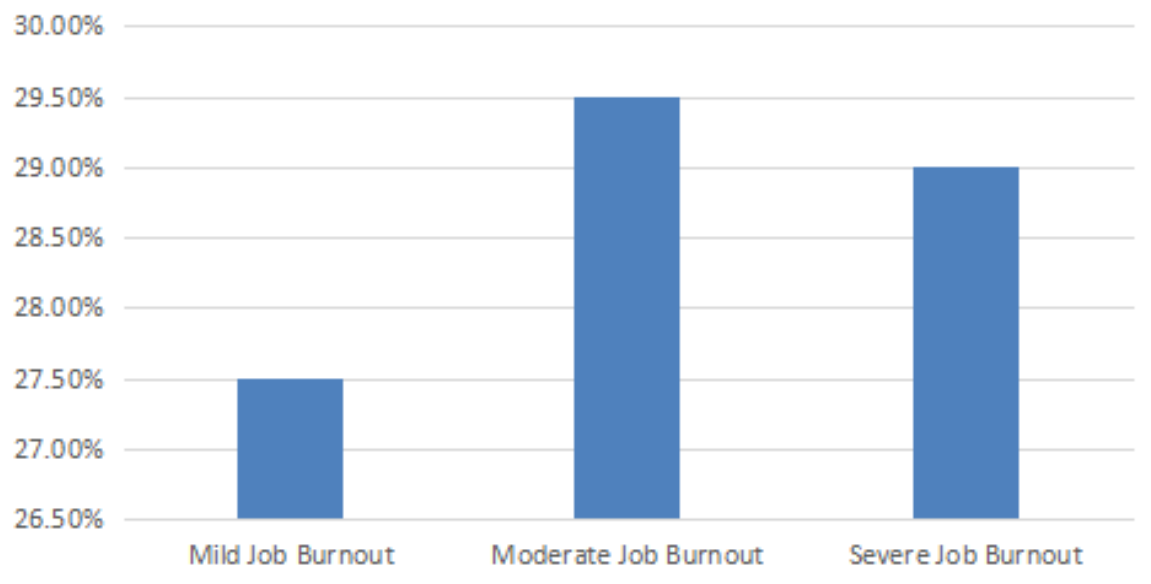

Figure 2. Job burnout of teachers in China.

\section{Causes of Low Professional Identity of Teachers in China}

At present, many primary and secondary school teachers are still under a lot of work pressure. Parents' high expectations for students, high requirements from society, fierce competition on teaching quality and graduation rates, continually-increasing class sizes, serious shortage of teachers have caused the overload of teachers. In addition to the busy work during the day, many teachers also need to stay up late to prepare lessons, correct students' homework, and write papers. Year after year, physical and psychological fatigues are easily produced under such overload of work and pressure, which resulted in many teachers' physical and mental conditions getting worse.

Actually, many teachers' psychological problems are not only caused by teachers' overwork and pressure, but also mostly by enormous pressure brought by the current assessment mechanism. In quite a number of primary and secondary schools in China, teachers' assessment, promotion, and salary are closely linked to students' test scores, which have been used as a primary means to arouse the enthusiasm of teachers for teaching. These schools use the passing rate of tests and the number of students entering key high schools and key universities to evaluate the performance of teachers who teach graduating class. For other teachers, the evaluation is dependent on the ranking of the classes in the grade, or the ranking of scores in the district. In other words, once the students' scores are not good, not only teachers would get criticized, but also their monthly income and career promotion would be affected.

At the same time, teachers' income is too low compared with their contribution to work. The survey carried out by Lu, Gao, Yan and Sun (2014) on the economic status and living condition of primary and secondary school teachers in the rural area of Hebei Province shows that more than $40 \%$ of teachers involved hope to raise revenue, more than $60 \%$ are not satisfied with their income, $86 \%$ said their salaries were only around 1,000 RMB ( $\$ 150$ ) to 3,000 RMB ( $\$ 450$ ), and only 10\% earned more than 3,000 RMB ( $\$ 450$ ) per month, while the house price there was between 2,000 RMB ( $\$ 150$ ) per square to 3,000 RMB (\$450) per square. Consequently, in the face of high cost of daily necessities and high prices of houses, life is hard, and life pressure is particularly heavy for teachers.

Nowadays, mental health issues in schools are increasingly taken seriously in China, but the attention is mainly focused on how to maintain and strengthen the mental health of students, while teachers' psychological health is almost neglected. The truth is, however, teachers' psychological problems have become increasingly 
prominent on account of the high pressure from work, life, and society (Sun, Wu, \& Wang, 2011). Additionally, poor psychological state of teachers is related to their lack of psychology knowledge. The experts in Psychological Development Research Institute of Peking University stated that only 9\% of courses offered by China's higher normal schools are about pedagogy and psychology, which is too low compared with 20\%-30\% in many developed countries (Sun, Wu, \& Wang, 2011). Furthermore, when teachers find they have some mental problems, there is no suitable channel for teachers to unbosom their feelings and worries. Many schools have psychological counselors only for students, but no institutes and experts specially dealing with teachers' mental problems, which makes things worse.

\section{Improving Teachers’ Economic Status}

The economic treatment of teachers is closely related with their interests, and has a significant impact on their career development and attractiveness of this profession, so the government should establish a guarantee mechanism to raise teachers’ economic status at all levels.

Firstly, the government should take effective measures to guarantee teachers' average income level not be lower than that of the national civil servants in some areas, which has already been clearly defined in Teachers Law of the People's Republic of China. Secondly, the government should perfect policies regarding rural teachers' salaries and career promotion. For example, providing higher income for teachers in rural areas in order to attract more talents to devote to long-term teaching there. Thirdly, the government and schools should set or perfect teachers' housing policy. For example, providing special apartments at cheaper price for prominent teachers and young teachers to arouse their enthusiasm for teaching career.

\section{Improving Teachers' Evaluation System}

Evaluation on teachers needs to be comprehensive. In the first place, schools should put an end to the evaluation of teachers just based on students' test scores and graduation rates, as students' test scores and graduation rates can not reflect a teacher's performance objectively. By conducting a scientific and reasonable evaluation of teachers' performance, schools could encourage teachers to take the initiative to pay more attention to the healthy growth of students, students' character development, and the cultivation of students' learning, living habits, and abilities. For example, in Shandong Province, communication with parents and students, help for learning difficulty students, the situation of students' learning and behavior habit, students' psychological health level, and sports passing rate are all incorporated to teacher's evaluation standard, which totally switches teacher's evaluation from scores-oriented to giving priority to all-round education (Liu \& Zhao, 2013).

Moreover, schools should diversify the main body of evaluation in order to guarantee the fairness and objectivity of evaluation, such as the four evaluation sources: experts, students, peers, and administrative staff. Usually, the data from administrative staff plays a very important part in evaluation, but there are a lot of weaknesses. On one hand, administrative staff are not students. They are not participants and direct consumers in teaching, so they could not decide whether a teacher's teaching is good or bad. On the other hand, because of the academic characteristics of course teaching, the evaluation from administrative staff is not entirely true to reflect the actual teaching. In fact, many teachers are usually afraid of the principal with a smattering of assessment to evaluate them. Therefore, if the peer-assessment or expert evaluation is employed, the effect of teacher evaluation will be better. For example, the Teacher Evaluation System applied in Cincinnati Public 
Schools in Ohio mainly uses peer mutual pattern, with principals' scores only account for 25\% of the teachers' final scores, which has obvious promoting-effect for both teachers and students (Tyler \& Tyler, 2012).

\section{Improving Teachers’ Mental Health}

Firstly, the administrative department of education should set up teachers' mental health research institute for professional research, dealing with counseling and management of teachers' psychological health problems. For example, opening a teachers' psychological health consultation service hot line for teachers to relieve stress is a practical solution. It is reported that Teachers' Psychological Consulting Center has been established in Chaoyang district, Beijing, in order to help teachers bear pressure. Up to March of 2011, 94 teachers had been to the center for face-to-face counseling, 2,516 counseling phones have been answered (Zhang, 2011). The consulting center now has become the main platform of teachers' psychological crisis intervention in Chaoyang district, Beijing.

Secondly, as managers of education, schools should strive to create a harmonious internal environment for teachers, organize confidential psychological test and investigation for teachers regularly, carry out psychological counseling together with social institutions. For example, schools can set up "psychological consulting room” especially for teachers or offer subsidies for teachers' psychological counseling. Schools can also invite experts to give lectures to teaching staff on how to do self-adjustments when meeting psychological problems.

In the past years, the government and schools have spent both great efforts and money on carrying out various kinds of teacher training programs. For example, the Ministry of Education has issued opinions about strengthening the primary and secondary school teachers training work, with special emphasis on rural areas. So, all the primary and secondary school teachers should take part in the training programs. Most of the training programs focus on new curriculum and teaching methodology, which to some extent successfully has made most teachers more professionally competent for their highly-required job. However, the inner-self of teachers, such as teachers' mental health, is still neglected in most training programs and the problems leading to low professional identity of teachers could not be solved just by additional teacher training.

On the other side, improving teachers' economic status, evaluation system, and mental health helps to enhance teachers' professional identity. Based on the statistics in the study of Teacher Evaluation System in Cincinnati Public Schools in Ohio, it is clear that a reasonable design of teachers' evaluation system will not only have a positive impact on the quality and identity of teachers, but also encourages the students to obtain a better academic achievement (Tyler \& Tyler, 2012).

\section{Conclusion}

Teachers' professional identity is closely related to the healthy and harmonious development of education, so government and schools should attach great importance to it. However, from teachers' dissatisfaction towards their work, their high job burnout level, and seriousness of mental health state, we can find the professional identity of teachers in China is very low. There are a lot of factors leading to this problem. Teachers' heavy and overtime work, as well as the unreasonable evaluation systems, has brought them heavy pressure. Besides, low income of teachers exposes them to pressures from life. What is worse, teachers have not been offered effective access to solutions when mental problems finally appear because of unbearable pressure. Therefore, by improving teachers' economic status, establishing scientific and reasonable evaluation 
systems for teachers, and improving mental heath condition, the government and schools could manage to solve the problem of low professional identity of teachers.

\section{References}

Azman, N. (2012). Review of academic and professional identities in higher education: The challenges of a diversifying workforce. Higher Education, 63(3), 387-389.

Cassel, R. N. (1984). Critical factors related to teacher burnout. Education, 105(1), 102-106.

Connelly, M., \& Clandinin, J. (Eds.). (1999). Shaping a professional identity: Stories of educational practice (pp. 65-70). New York, N.Y.: Teachers College Press.

E, F. (2013). Teachers: Behind the happiest jobs in the public eye. Xiaokang, 11, 66-68.

Goodson, F. (1994). Teacher's professional knowledge: Constructing identity and community. Teacher Education Quarterly, 21(1), 85-105.

He, P., Yang, Z., Jiang, W., Yang, Y. G., \& Wang, T. (2016). A survey of primary and secondary school teachers’ mental health: Take Bijie as an example. Asian-Pacific Education, 20, 257-260.

Li, C. P. (2005). The investigation report on teachers' survival by sina education: Conditions are grim. Sina Education. Retrieved June 17, 2016, from http://edu.sina.com.cn/l/2005-09-09/1653126581.html

Li, Y. X., Li, Y. M., \& Shen, J. L. (2012). Teachers' organization identity and professional identity. Journal of Henan University: Social and Science Edition, 2, 118-122.

Lian, Q. Q., \& Liao, H. W. (2008). A teacher suspected of suicide because of depression. Dayoo. Retrieved July 20, 2016, from http://news.dayoo.com/guangzhou/200810/29/53872_4315250.htm

Liao, Z. R., \& Wang, D. H. (2015). A teacher committed suicide in Hainan. Tencent News. Retrieved July 20, 2016, from http://news.qq.com/a/20150417/035625.htm

Liu, Y. D. (May 28, 2012). The suicide of a teacher in Guantao. The Beijing News. Retrieved June 17, 2016, from http://www.bjnews.com.cn/news/2012/05/28/201450.html

Liu, S. J., \& Zhao, D. C. (2013). Teacher evaluation in China: Latest trends and future Directions. Educational Assessment, Evaluation and Accountability, 25, 231-250.

Lu, L. J., Gao, Q., Yan, H. M., \& Sun, Y. Z. (2014). Rural teachers' welfare treatment needs to be improved: A survey report on the income, housing condition, and medical care of rural primary and secondary school teachers in central and southern Hebei Province. China Education Daily. Retrieved June 17, 2016, from http://paper.jyb.cn/zgjyb/html/2014-11/01/content -425522.htm?div=-1

Peterson, K. (1995). Teacher evaluation: A comprehensive guide to new directions and practice (pp. 35-39). Thousand Oaks, Calif.: Corwin Press.

Sun, W., Wu, H., \& Wang, L. (2011). Occupational stress and its related factors among university teachers in China. Journal of Occupational Health, 53(4), 280-286.

Tyler, E., \& Tyler, J. (2012). Can teacher evaluation improve teaching?. Education Next. Retrieved June 17, 2016, from http://educationnext.org/files/ednext_20124_taylortyler.pdf

Zhang, L. (2011). More than $60 \%$ of teachers are poor in mental health. Jinghua Times. Retrieved June 2, 2016, from http://paper.people.com.cn/jhsb/html/2011-04/12/content_792761.htm

Zhang, J. J., \& Lu, A. T. (2008). Review of teachers' mental health research in China since 1994. Frontiers of Education in China, 3(4), 623-638. 